\title{
Deficit irrigation and maturation stage influence quality and flavonoid composition of 'Valencia' orange fruit
}

\author{
Filipa S Grilo, ${ }^{a}$ Vita Di Stefano ${ }^{b}$ and Riccardo Lo Bianco ${ }^{a^{*}}{ }_{\odot}$
}

\begin{abstract}
BACKGROUND: Effects of continuous deficit irrigation (DI) and partial rootzone drying (PRD) treatments (50\% ETc) in comparison with full irrigation (Cl, $100 \%$ ETc) were investigated during 'Valencia' orange fruit maturation. Ultra-high-performance liquid chromatography/high-resolution mass spectrometry was used to quantify hesperidin, narirutin, tangeritin, nobiletin, didymin and neoeriocitrin in the fruit juice and peel.

RESULTS: No significant effect of irrigation was found on yield, juice soluble solids or acidity. Juice color was not influenced by irrigation or harvest date, whereas peel color increased during maturation and was more pronounced in $\mathrm{Cl}$ and PRD fruits. Juice acidity reached a peak in May, while soluble solids increased linearly throughout maturation. Hesperidin was the major flavanone detected during maturation, with concentrations 200-fold higher in the fruit peel than in the juice. In the peel, narirutin, didymin and neoeriocitrin decreased while hesperidin, nobiletin and tangeritin increased with maturation. Narirutin synthesis in the orange fruit was insensitive to irrigation strategy. In fruit peels, PRD and DI induced the decline of hesperidin, nobiletin and tangeritin only in June, whereas in the juice, deficit irrigation treatments induced an increase in hesperidin and didymin.

CONCLUSION: These results suggest that deficit irrigation, in particular the conditions imposed with PRD, may cause a significant accumulation shift of total flavonoids from the fruit peel into the juice, with a positive impact on juice quality and nutritional value. Fruit compositional changes during maturation also suggest that late harvest can improve fruit palatability and nutritional quality under the cultural and environmental conditions of this study.

(c) 2016 Society of Chemical Industry
\end{abstract}

Keywords: Citrus sinensis; hesperidin; partial rootzone drying; peel color; soluble solids; UHPLC/HESI-MS

\section{INTRODUCTION}

Fruit quality is related to physical properties (i.e. size, shape, color, texture, seed number) and chemical components (i.e. sugars, acids, flavor compound volatiles, vitamin C) of the fruit. ${ }^{1}$ Chemical and physical properties change during maturation, forming final fruit quality at harvest. When temperatures go down and day length decreases, peel coloration is triggered by the degradation of chlorophyll and the synthesis of carotenoids. ${ }^{1}$ During pulp maturation, total soluble solids (mainly carbohydrates and minor quantities of organic acids, proteins, lipids and minerals) increase and titratable acidity decreases, primarily owing to the catabolism of citric acid. ${ }^{2,3}$ In addition to maturity indices, harvest time and pomological traits, nutritional and antioxidant properties have become important parameters for quality appraisal, as they show an increasing impact on consumer choices. ${ }^{4}$

The majority of citrus production occurs in arid and semi-arid subtropical areas. In these areas, low water availability may represent a major limiting factor for yield and fruit quality, as it affects a wide range of plant physiological and developmental processes. Indeed, water deficit decreases crop loads of navel oranges. ${ }^{6}$ In established orchards, irrigation management, along with rootstock, may be a suitable tool to manipulate the final fruit quality at harvest. ${ }^{5}$ Sensitivity to water deficit may vary according to phenological stages and can be managed to improve fruit quality. ${ }^{7}$ If water deficit is applied during summer, when fruits are at the initial stage of development, a subsequent rehydration due to winter rainfall may result in no significant changes in final fruit size and juice content..$^{8,9}$ In orange, if deficit is applied at later physiological stages, plant water stress is correlated positively with total soluble solids and titratable acids and negatively with juice percentage, with no overall effect on maturation index. ${ }^{10}$ In addition, the flavonoid content of early-maturing 'Navelina' oranges was not influenced by moderate deficit irrigation applied during late fruit growth. ${ }^{11}$

Partial rootzone drying (PRD) is a deficit irrigation strategy based on alternating irrigation of one side of the rootzone, and it aims at maintaining reduced stomatal conductance and avoiding

\footnotetext{
* Correspondence to: $R$ Lo Bianco, Department of Agricultural and Forest Sciences, University of Palermo, Viale delle Scienze, I-90128 Palermo, Italy. E-mail: riccardo.lobianco@unipa.it

a Department of Agricultural and Forest Sciences, University of Palermo, Italy

b Department of Biological, Chemical and Pharmaceutical Science and Technology, University of Palermo, Italy
} 
water stress. ${ }^{12-16}$ The impact of PRD has been largely studied in grapevine ${ }^{17,18}$ and in many other fruit crops. It is generally accepted that PRD improves irrigation water use efficiency, often without significant yield or fruit quality reductions when compared with normal irrigation methods. ${ }^{5,13,16,18-20}$ In citrus, the literature suggests that irrigation volume rather than irrigation placement may affect yield and fruit size, posing some doubts on the efficacy of PRD in these crops., ${ }^{6,21,22}$

Phenolic compounds are one of the largest and most widely distributed groups of secondary metabolites in plants, ${ }^{23}$ with flavonoids being the most abundant phenolic compounds in nature. ${ }^{24}$ The presence of secondary metabolites in orange fruits contributes to their particular flavor and their high nutritional value, and sweet oranges can have the highest percentage of phenolic compounds among fruits. ${ }^{24}$ Flavonoids are indeed considered an additional factor in orange fruit quality evaluations owing to their pharmacological and physiological activity in both human and plant health. ${ }^{25}$ In citrus, different types of flavonoids have been identified, such as flavanones, flavones, flavonols and anthocyanins, with flavanone glycosides being the most common. ${ }^{26-28}$ Recently, ultra-high-performance liquid chromatography/high-resolution OrbiTrap mass spectrometry has been used for the rapid and accurate identification of constituents in plant extracts. ${ }^{29}$

In orange juice, major flavonoids are the tasteless flavanones narirutin, hesperidin and didymin. ${ }^{26,27,30,31}$ In the peel of 'Valencia' oranges, the major flavonoids are hesperidin and narirutin. ${ }^{27}$ In juice sacs, their content increases during fruit development until maturation, then it decreases. ${ }^{26}$

Flavonoid profile and concentration vary according to several factors such as genetic material, harvest time or constitutive parts of the fruit. ${ }^{25}$ Environmental factors can also influence the levels of secondary metabolites during citrus fruit development. ${ }^{32}$ Studying changes in quality parameters in general, and flavonoids in particular, in response to fruit constitutional part, maturation stage and irrigation management can contribute to a better understanding of the mechanisms regulating fruit quality; this will ultimately contribute to the improvement of the nutritional and health properties of the orange fruit.

\section{EXPERIMENTAL}

\section{Plant material and sampling}

This investigation was carried out in an experimental plot of the Department of Agricultural and Forest Sciences, University of Palermo, Italy $\left(30.06^{\circ} \mathrm{N}, 13.21^{\circ} \mathrm{E}, 31 \mathrm{~m}\right.$ a.s.l.). Forty-eight adult orange trees (Citrus sinensis cv. Valencia) grafted on sour orange (Citrus aurantium L.), spaced at $4 \mathrm{~m} \times 4 \mathrm{~m}$, and trained to raised globe canopy ( $1 \mathrm{~m}$ from the ground to $2.8 \mathrm{~m}$ full height) were used. Starting in summer 2007, three irrigation treatments were imposed in the experimental plot: irrigation with volumes corresponding to $100 \%$ of crop evapotranspiration applied to the entire rootzone $(\mathrm{Cl})$, partial rootzone drying (PRD) with $50 \%$ of $\mathrm{Cl}$ water applied to one alternated side of the rootzone, and continuous deficit irrigation (DI) with $50 \%$ of $\mathrm{Cl}$ water applied to the entire rootzone. Trees in the experimental plot were labeled according to a randomized block design with four blocks of 12 trees each. Except for irrigation, all trees in the experiment were under the same conventional cultural care, with biennial pruning and last pruning in June 2013. In this work, only data from the 2013-2014 cropping season are presented.
On 8 April, 5 May and 3 June 2014, ten fruits per tree were randomly sampled from eight trees (two in each block) in each treatment, for a total of 240 fruits and 24 trees (replicates), and were used for subsequent analysis. At harvest (3 June), fruits were collected from each tree, counted and weighed in order to determine tree crop load and yield.

\section{Determination of fruit quality}

Fruit samples were taken to the laboratory for qualitative determinations such as weight, peel color, juice yield, juice color, total soluble solids (TSS) and titratable acidity (TA). Each set of fruits was washed and cleaned, photographed and weighed, and the juice was extracted using a reamer juicer. Part of the juice (pooled from the ten fruits) was stored at $-18{ }^{\circ} \mathrm{C}$ until flavonoid quantification. The remaining juice was used to determine juice color, TSS and TA.

Pictures for peel and juice color were taken under controlled light conditions with a Fujifilm FinePix F600EXR digital camera (Fujifilm Holdings Corporation, Tokyo, Japan). Digital images were labeled and analyzed using an algorithm that converts images from RGB to CIE $1976 L^{*} a^{*} b^{*}$ format, extracts the fruit from the image (removing the image background) and quantifies color characteristics as the weighted distance of each pixel in the image from a reference sample (best colored area interactively chosen from a well-colored fruit). The output is an index ranging from 0 (no orange) to 1 (best orange).

Juice yield of each fruit was calculated as the percentage of juice weight over the corresponding fruit weight. Juice $\mathrm{pH}$ and TA were determined using a Crison Compact titrator (Crison Instruments, SA, Barcelona, Spain), and acidity was converted into g citric acid per $100 \mathrm{~mL}$ juice. Juice TSS was determined using an Atago PR32 digital refractometer (Atago Co., Ltd, Tokyo, Japan) and expressed in ${ }^{\circ}$ Brix.

\section{Flavonoid extraction and quantification}

Fruit peel from all fruits collected from each tree was pooled and ground in a blender, and a $20 \mathrm{~g}$ aliquot was sampled and mixed with $40 \mathrm{~mL}$ of methanol for flavonoid extraction. After $48 \mathrm{~h}$, the eluate was concentrated to dryness in a rotary evaporator at $40^{\circ} \mathrm{C}$. The dry extract was re-dissolved in methanol/water (80:20 $\mathrm{v} / \mathrm{v}$ ) and diluted to $0.005 \mathrm{~g} \mathrm{~mL}^{-1}$. Fresh juice from the same fruit samples was centrifuged at $2500 \times \mathrm{g}$ for $15 \mathrm{~min}$, then $1 \mathrm{~mL}$ of supernatant was diluted in $4 \mathrm{~mL}$ of methanol/water $(70: 30 \mathrm{v} / \mathrm{v})$, filtered through a $0.45 \mu \mathrm{m}$ polypropylene filter and stored at $-18^{\circ} \mathrm{C}$ until subsequent analysis

Phenolic compounds were identified by ultrahigh-performance liquid chromatography/heated electrospray ionization mass spectrometry (UHPLC/HESI-MS). UHPLC analysis was conducted using a Dionex Ultimate 3000 system (Dionex Softron $\mathrm{GmbH}$, Germering, Germany) equipped with an autosampler controlled by Chromeleon 7.2 software (Thermo Fisher Scientific, Bremen, Germany). A UHPLC column (Phenomenex Luna C18(2), $50 \mathrm{~mm} \times 1$ $\mathrm{mm}, 2.5 \mu \mathrm{m}$ ) was used for separation of the selected compounds at $35^{\circ} \mathrm{C}$. The mobile phases used were $(\mathrm{A}) 0.1 \%(\mathrm{v} / \mathrm{v})$ formic acid in water and (B) methanol. The gradient elution program was as follows: $0-5 \mathrm{~min}, 10 \% \mathrm{~B} ; 5-50 \mathrm{~min}$, linear increase to $99 \% \mathrm{~B}$; $50-56 \mathrm{~min}, 10 \% \mathrm{~B}$, coming back to the initial conditions until full stabilization. The column temperature was set at $30{ }^{\circ} \mathrm{C}$ and the

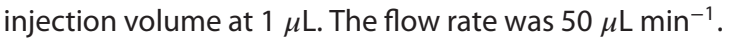

An HESI ion source was used for the ionization. The HESI parameters were optimized as follows: sheath gas flow rate at 30 arbitrary units, auxiliary gas unit flow rate at 10 arbitrary units, capillary 
temperature at $250{ }^{\circ} \mathrm{C}$, auxiliary gas heater temperature at 150 ${ }^{\circ} \mathrm{C}$, spray voltage at $2.8 \mathrm{kV}$ and $\mathrm{S}$ lens radio frequency level at 50 . The MS runs were carried out in positive and negative ion HESI modes in the mass range $\mathrm{m} / \mathrm{z} 180-2000$ and the instrument was calibrated daily in both ionization modes. Data were acquired simultaneously in full scan. The automatic gain control was set as 'balanced' with a maximum injection time of $200 \mathrm{~ms}$. The data were processed with Xcalibur 2.1 software (Thermo Fisher Scientific). HESI-MS spectra in positive and negative ionization modes yield the singly protonated ion $[\mathrm{M}+\mathrm{H}]^{+}$and the deprotonated ion $[\mathrm{M}-\mathrm{H}]^{-}$, respectively. HESI recorded in positive ion mode is the most common procedure for the analysis of didimin, nobiletin and tangeretin. Neoeriocitrin, narirutin and hesperidin were analyzed in negative ion mode.

Standard stock solutions were prepared individually at a concentration of $0.1 \mathrm{mg} \mathrm{mL}^{-1}$ by dissolving $1 \mathrm{mg}$ of each standard in $10 \mathrm{~mL}$ of methanol/water (70:30 v/v). Stock solutions were diluted to obtain five different concentrations of standard solutions in the range between 7.5 and $0.25 \mathrm{mg} \mathrm{mL}^{-1}$. All solutions were corrected for purity, and no internal standard was used in this study. Ratios of the peak areas were calculated and plotted against the corresponding concentrations of the standard compounds using linear regression (least squares) to generate standard curves. Neoeriocitrin, narirutin, hesperidin, didymin, nobiletin and tangeretin were purchased from Extrasynthese (Genay, France). Methanol (LC/MS grade) was purchased from Biosolve B.V. (Valkenswaard, The Netherlands) and formic acid (98-100\%) from VWR International B.V. (Roden, The Netherlands).

\section{Data analysis}

All data were tested by analysis of variance (ANOVA) using SYSTAT procedures (Systat Software Inc., Chicago, IL, USA). Significant irrigation effects were followed by Tukey's multiple comparison test at $P \leq 0.05$, whereas significant effects of harvest date were tested by orthogonal polynomial contrasts. Relationships between parameters were established by linear and nonlinear regression analysis.

\section{RESULTS AND DISCUSSION}

At harvest, no differences in crop load, yield and fruit weight were found among irrigation treatments (Table 1). Despite the lack of statistical differences, it is worth noticing that $\mathrm{Cl}$ tended to produce a greater number of fruits per tree than PRD, whereas PRD tended to produce larger fruits than $\mathrm{Cl}$. This crop load/fruit weight compensation mechanism in response to PRD has also been observed in apple, especially with late-ripening cultivars. ${ }^{33}$ The lack of an irrigation effect on yield parameters can be explained by a recovery of fruit growth after winter and spring rainfalls. Similar results and explanations were reported by Goldhamer and Salinas ${ }^{8}$ in a study with 'Frost Nucellar Valencia' orange where deficit irrigation was applied in several periods during fruit growth. Also, a number of studies with orange showed no significant effect of PRD irrigation on yield, even when the irrigation treatment was applied during the entire fruit growth period. ${ }^{6,34}$ Overall, these results confirm previous research suggesting that summer is a suitable period for deficit irrigation in orange fruit production, as already seen for 'Clementina de Nules' citrus. ${ }^{35,36}$ Other studies with citrus report significant reductions in yield and/or fruit size in response to deficit irrigation. ${ }^{21}$ The presence or absence of an effect of irrigation on yield may depend on both the degree and duration of
Table 1. Crop load, yield and average fruit weight of 'Valencia' trees under conventional irrigation $(\mathrm{Cl})$, continuous water deficit $(\mathrm{DI})$ and partial rootzone drying (PRD)

\begin{tabular}{lccc|} 
Irrigation & $\begin{array}{c}\text { Crop load } \\
\text { (fruits per tree) }\end{array}$ & $\begin{array}{c}\text { Yield } \\
\text { (kg per tree) }\end{array}$ & $\begin{array}{c}\text { Fruit } \\
\text { weight (g) }\end{array}$ \\
\hline $\mathrm{Cl}$ & $149 \pm 36$ & $27.1 \pm 6.0$ & $189 \pm 8$ \\
$\mathrm{PRD}$ & $111 \pm 28$ & $19.3 \pm 4.2$ & $192 \pm 12$ \\
$\mathrm{DI}$ & $137 \pm 33$ & $23.8 \pm 5.5$ & $182 \pm 6$ \\
$P$ value & 0.552 & 0.506 & 0.722 \\
\hline
\end{tabular}

Values are mean \pm standard error $(n=48)$. $P$ values from ANOVA are reported.

plant water stress. ${ }^{34}$ In addition, there was no significant irrigation effect on juice yield, which was about $53 \%$ of fruit weight (data not shown). The latter is in accordance with results found in navel oranges by Goldhamer and Salinas ${ }^{8}$ and in 'Clementina de Nules' by Velez et al. ${ }^{9}$ and Ballester et al..$^{36}$ This means that the observed changes in juice quality are true responses to harvest date and are associated with fruit maturation or due to metabolic differences triggered by irrigation strategies, rather than simply due to fruit dehydration and juice concentration.

Changes in fruit quality parameters were analyzed in response to irrigation treatment and maturation stage (harvest date), and no interaction was found between these two factors. Therefore the two main factors were analyzed separately.

Date of harvest significantly affected peel color, with a linear increase in orange coloration from April to June (Table 2). It is in fact known that, as fruits mature, peel color gradually shifts from green to orange. ${ }^{37}$ Although sugar/acid ratio is generally recognized as the best maturity index in citrus, ${ }^{38}$ a significant correlation between peel color and TSS/TA was found in this study $(r=0.396$, $P=0.002$ ), suggesting that peel color may also be an indicator of fruit ripening stage. Peel color was also significantly affected by irrigation, with $\mathrm{Cl}$ and $\mathrm{PRD}$ fruits showing more intense orange peels than DI fruits (Table 2). This response may just indicate a delay in DI fruit maturation or, more likely, a reduction in pigment formation, perhaps connected to lowered nutrients/reserves in DI trees. ${ }^{39}$

Table 2. Peel and juice color indices in fruit of 'Valencia' trees at different harvest dates and under conventional irrigation $(\mathrm{Cl})$, continuous water deficit (DI) and partial rootzone drying (PRD)

\begin{tabular}{|lcc|} 
Harvest & Peel color index & Juice color index \\
\hline 8 April & $0.932 \pm 0.0012$ & - \\
5 May & $0.937 \pm 0.0011$ & $0.946 \pm 0.0009$ \\
3 June & $0.942 \pm 0.0013$ & $0.948 \pm 0.0009$ \\
$P$ value & $<0.001$ & 0.122 \\
Polynomial contrast & Linear & - \\
\hline Irrigation & Peel color index & Juice color index \\
\hline Cl & $0.938 \pm 0.0011 a$ & $0.948 \pm 0.0013$ \\
PRD & $0.938 \pm 0.0014 a$ & $0.946 \pm 0.0012$ \\
DI & $0.935 \pm 0.0015 b$ & $0.947 \pm 0.0008$ \\
$P$ value & 0.043 & 0.745 \\
\hline
\end{tabular}

Values are mean \pm standard error $(n=24)$. $P$ values for main effects and polynomial contrasts are reported. When present, different letters indicate significant differences among irrigation treatments for each parameter (Tukey's test, $P \leq 0.05$ ). 
Table 3. Juice quality of 'Valencia' orange fruit at different harvest dates and under conventional irrigation (Cl), continuous water deficit (DI) and partial rootzone drying (PRD)

\begin{tabular}{lccc} 
Harvest & TSS (\%) & TA (g per $100 \mathrm{~mL})$ & TSS/TA \\
\hline 8 April & $12.2 \pm 0.21$ & $1.04 \pm 0.022$ & $11.6 \pm 0.33$ \\
5 May & $12.5 \pm 0.18$ & $1.07 \pm 0.016$ & $11.7 \pm 0.13$ \\
3 June & $13.0 \pm 0.16$ & $1.02 \pm 0.018$ & $12.9 \pm 0.33$ \\
P value & 0.011 & 0.015 & $<0.001$ \\
Polynomial contrast & Linear & Quadratic & Linear Quadratic \\
\cline { 2 - 4 } Irrigation & TSS (\%) & TA (g per $100 \mathrm{~mL})$ & TSS/TA \\
\hline CI & $12.8 \pm 0.23$ & $1.06 \pm 0.016$ & $12.1 \pm 0.19$ \\
PRD & $12.4 \pm 0.24$ & $1.05 \pm 0.015$ & $11.9 \pm 0.22$ \\
DI & $12.5 \pm 0.22$ & $1.02 \pm 0.025$ & $12.1 \pm 0.44$ \\
P value & 0.399 & 0.113 & 0.639 \\
\hline
\end{tabular}

Values are mean \pm standard error $(n=24)$. $P$ values for main effects and polynomial contrasts are reported. When present, different letters indicate significant differences among irrigation treatments for each parameter (Tukey's test, $P \leq 0.05$ ). TSS, total soluble solids; TA, titratable acidity.

Table 4. Narirutin, didymin and neoeriocitrin content $\left(\mathrm{mg} \mathrm{g}^{-1}\right)$ in peel of 'Valencia' oranges at different harvest dates and under conventional irrigation $(\mathrm{Cl})$, continuous water deficit (DI) and partial rootzone drying (PRD)

\begin{tabular}{|c|c|c|c|}
\hline Harvest & Narirutin & Didymin & Neoeriocitrin \\
\hline 8 April & $4.25 \pm 0.24$ & $0.64 \pm 0.04$ & $0.015 \pm 0.005$ \\
\hline 5 May & $7.10 \pm 0.67$ & $1.06 \pm 0.12$ & $0.013 \pm 0.004$ \\
\hline 3 June & $0.36 \pm 0.05$ & $0.12 \pm 0.03$ & $0.000 \pm 0.000$ \\
\hline$P$ value & $<0.001$ & $<0.001$ & 0.007 \\
\hline \multicolumn{3}{|c|}{ Polynomial contrast Linear Quadratic Linear Quadratic } & Linear \\
\hline Irrigation & Narirutin & Didymin & Neoeriocitrin \\
\hline $\mathrm{Cl}$ & $3.53 \pm 0.60$ & $0.57 \pm 0.09$ & $0.006 \pm 0.004$ \\
\hline PRD & $3.52 \pm 0.71$ & $0.56 \pm 0.11$ & $0.009 \pm 0.004$ \\
\hline DI & $4.04 \pm 0.91$ & $0.61 \pm 0.14$ & $0.011 \pm 0.004$ \\
\hline$P$ value & 0.152 & 0.457 & 0.364 \\
\hline
\end{tabular}

Values are mean \pm standard error $(n=24)$. $P$ values for main effects and polynomial contrasts are reported. When present, different letters indicate significant differences among irrigation treatments for each compound (Tukey's test, $P \leq 0.05$ ).

On the contrary, juice color was not affected by either date of harvest or irrigation (Table 2), indicating that this trait is relatively insensitive to fruit maturation changes and irrigation strategies, probably because internal juice color is less influenced by the synthesis of color pigments such as carotenoids and xanthophylls. This is likely due to the influence of light on pigment synthesis. Fruit skin is in fact more prone and susceptible to changes in color, as the first step of carotenoid biosynthesis (i.e. formation of phytoene) is stimulated by light. .0, $^{41}$

In fruit juice, TSS, TA and TSS/TA ratio were affected by harvest date (Table 3 ). Changes in juice quality parameters over time showed that TSS increased linearly from 8 April to 3 June. Unexpectedly, TA exhibited a quadratic response, with an increase in the second harvest and a subsequent reduction in the third. A significant linear and quadratic contrast for TSS/TA ratio suggests a nonlinear increase over time. Irrigation treatments showed no significant effect on orange juice internal quality (Table 3). The lack of
Table 5. Hesperidin, nobiletin and tangeritin content $\left(\mathrm{mg} \mathrm{g}^{-1}\right)$ in peel of 'Valencia' oranges at different harvest dates and under conventional irrigation $(\mathrm{Cl})$, continuous water deficit (DI) and partial rootzone drying (PRD)

\begin{tabular}{|ccccc} 
Harvest & Irrigation & Hesperidin & Nobiletin & Tangeritin \\
\hline 8 April & $\mathrm{Cl}$ & $11.5 \pm 0.76$ & $1.14 \pm 0.12$ & $0.06 \pm 0.01$ \\
& $\mathrm{PRD}$ & $9.97 \pm 0.99$ & $0.78 \pm 0.15$ & $0.05 \pm 0.02$ \\
& $\mathrm{DI}$ & $10.8 \pm 0.60$ & $0.92 \pm 0.11$ & $0.05 \pm 0.02$ \\
5 May & $\mathrm{Cl}$ & $20.3 \pm 1.36$ & $2.23 \pm 0.30$ & $0.16 \pm 0.04$ \\
& $\mathrm{PRD}$ & $18.3 \pm 1.36$ & $2.26 \pm 0.18$ & $0.11 \pm 0.04$ \\
& $\mathrm{DI}$ & $18.7 \pm 1.26$ & $1.83 \pm 0.12$ & $0.03 \pm 0.02$ \\
3 June & $\mathrm{Cl}$ & $31.7 \pm 2.99 \mathrm{a}$ & $9.17 \pm 0.99 \mathrm{a}$ & $1.69 \pm 0.29 \mathrm{a}$ \\
& $\mathrm{PRD}$ & $20.1 \pm 1.67 \mathrm{~b}$ & $4.11 \pm 0.57 \mathrm{~b}$ & $0.66 \pm 0.12 \mathrm{~b}$ \\
& $\mathrm{DI}$ & $21.4 \pm 1.50 \mathrm{~b}$ & $4.28 \pm 0.45 \mathrm{~b}$ & $0.48 \pm 0.08 \mathrm{~b}$ \\
Harvest $\times$ irrigation & 0.007 & $<0.001$ & $<0.001$
\end{tabular}

Values are mean \pm standard error $(n=8)$. $P$ values for interaction between harvest date and irrigation are reported. When present, different letters indicate significant differences among irrigation treatments for each flavonoid and harvest date (Tukey's test, $P \leq 0.05$ ).

Table 6. Flavonoid content $\left(\mu \mathrm{g} \mathrm{mL}^{-1}\right)$ in juice of 'Valencia' oranges at different harvest dates and under conventional irrigation $(\mathrm{Cl})$, continuous water deficit (DI) and partial rootzone drying (PRD)

\begin{tabular}{|lccc|} 
Harvest & Narirutin & Hesperidin & Didymin \\
\hline 8 April & $42.9 \pm 2.19$ & $88.1 \pm 3.81$ & $9.7 \pm 0.67$ \\
5 May & $51.1 \pm 2.08$ & $101.6 \pm 5.31$ & $12.1 \pm 0.62$ \\
3 June & $49.0 \pm 2.63$ & $112.7 \pm 7.12$ & $12.0 \pm 0.85$ \\
P value & 0.023 & $<0.001$ & 0.042 \\
Polynomial contrast & Quadratic & Linear & Linear \\
\hline Irrigation & Narirutin & Hesperidin & Didymin \\
\hline Cl & $45.0 \pm 2.06$ & $93.1 \pm 5.55 b$ & $9.9 \pm 0.64 \mathrm{~b}$ \\
PRD & $47.3 \pm 1.85$ & $106.9 \pm 5.48 \mathrm{a}$ & $11.9 \pm 0.68 \mathrm{ab}$ \\
DI & $52.1 \pm 3.01$ & $104.3 \pm 6.55 \mathrm{a}$ & $13.1 \pm 0.81 \mathrm{a}$ \\
$P$ value & 0.121 & 0.020 & 0.012 \\
\hline
\end{tabular}

Values are mean \pm standard error $(n=24)$. $P$ values for main effects and polynomial contrasts are reported. When present, different letters indicate significant differences among irrigation treatments for each compound (Tukey's test, $P \leq 0.05$ )

an irrigation effect on TSS and TA content in our juice is in contrast to other results found in the literature on other citrus varieties, ${ }^{34-36}$ where deficit irrigation had increased TA and TSS. None of these studies was conducted with 'Valencia' oranges, so it is possible that the lack of an irrigation effect on juice quality is cultivar-specific and likely related to the early stage of fruit growth at the time irrigation was applied.

Regardless of harvest date and irrigation treatment, hesperidin was the most abundant flavonoid in the 'Valencia' fruit peel, followed by nobiletin and narirutin (Tables 4 and 5). This flavonoid profile is in accordance with previous studies. ${ }^{27}$ During fruit maturation, peel narirutin and didymin exhibited a nonlinear (quadratic) decrease with a peak in May, while neoeriocitrin presented a linear decrease (Table 4). Furthermore, narirutin, didymin and neoeriocitrin content in the peel was not significantly affected by the different irrigation treatments (Table 4). On the other hand, hesperidin, nobiletin and tangeritin tended to increase during maturation and were significantly reduced 

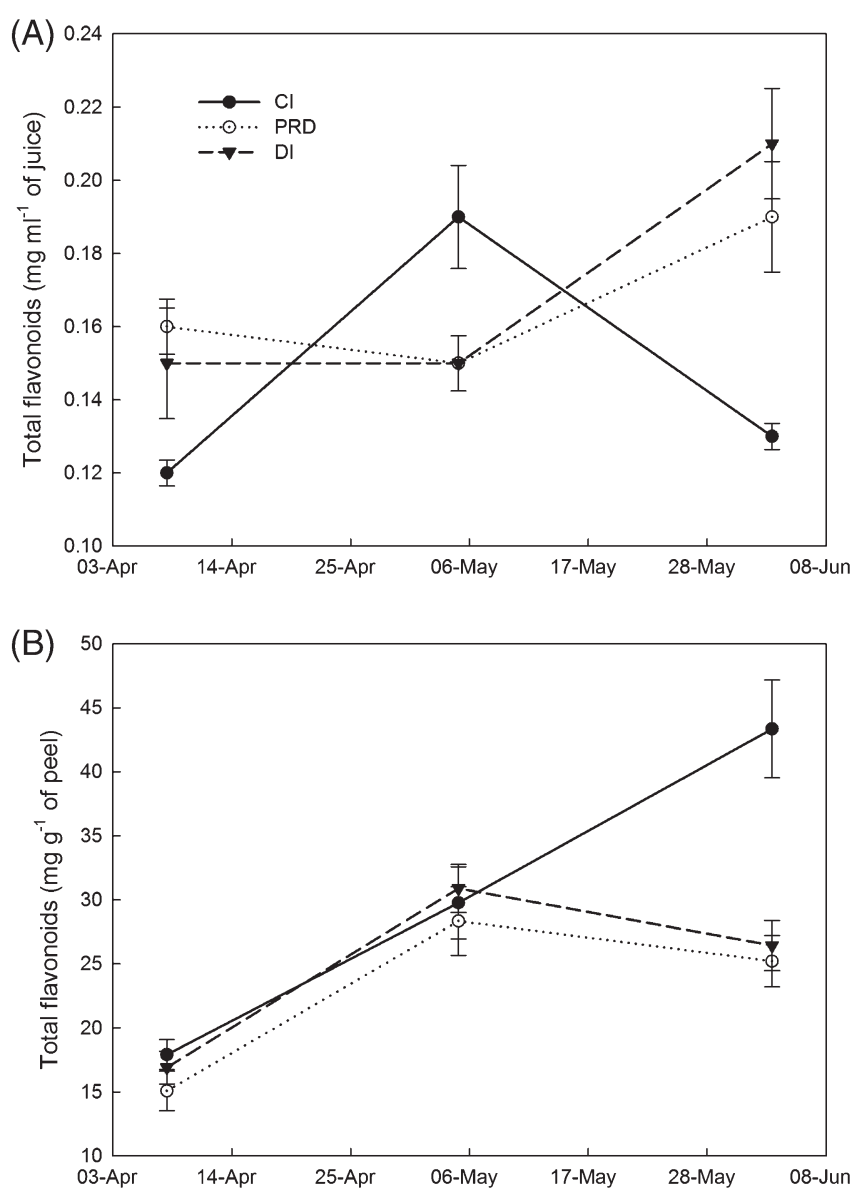

Figure 1. Total flavonoid content in (A) juice and (B) peel of 'Valencia' oranges at different harvest dates and under conventional irrigation $(\mathrm{Cl})$, continuous water deficit (DI) and partial rootzone drying (PRD). Error bars indicate standard errors of the means $(n=8)$.

by deficit treatments, but only at the end of maturation (June) (Table 5).

Regardless of harvest date and irrigation treatment, hesperidin was the most abundant flavonoid in our 'Valencia' orange juices, followed by narirutin and didymin (Table 6). As described in the peel, these results are in accordance with the flavonoid profile reported for sweet oranges. ${ }^{27,42}$ During maturation, hesperidin and didymin showed a linear increase, while narirutin followed a quadratic increase with a peak in May (Table 6). Contrary to what was observed in the peel, deficit irrigation significantly increased flavonoid content in the juice. In particular, hesperidin was highest in PRD and lowest in $\mathrm{Cl}$, whereas didymin was highest in $\mathrm{DI}$ and lowest in $\mathrm{Cl}$ fruit juice. Although the flavonoids studied do not contribute to juice taste, they have been proven to be positively related to better fruit storage due to their antioxidant activity ${ }^{43,44}$ and higher nutraceutical quality of the juice. ${ }^{45}$

Narirutin in the fruit juice and peel was not significantly affected by irrigation treatments, showing that the synthesis of this flavanone is insensitive to tree water status in stage II of fruit growth. On the contrary, deficit irrigation, in particular the mild deficit conditions imposed with PRD, seems to cause a significant and useful accumulation shift of total flavonoids from the fruit peel into the juice (Fig. 1), with a positive impact on the nutritional value of the edible fruit portion. An overall look at compositional changes during fruit maturation also suggests that juice quality and nutritional value can be improved if fruits are harvested in early June under the cultural and environmental conditions of this study.

\section{REFERENCES}

1 Iglesias DJ, Cercós M, Colmenero-Flores JM, Naranjo MA, Ríos G, Carrera E et al., Physiology of citrus fruiting. Braz J Plant Physiol 19:333-362 (2007).

2 Baldwin EA, Citrus fruit, in Biochemistry of Fruit Ripening, ed. by Seymour GB, Taylor JE and Tucker GA. Springer, Dordrecht, pp. 107-149 (1993).

3 Bermejo A and Cano A, Analysis of nutritional constituents in twenty citrus cultivars from the Mediterranean area at different stages of ripening. Food Nutr Sci 3:639-650 (2012).

4 Kelebek H, Selli S, Canbas A and Cabaroglu T, HPLC determination of organic acids, sugars, phenolic compositions and antioxidant capacity of orange juice and orange wine made from a Turkish cv. Kozan. Microchem J 91:187-192 (2009).

5 Romero P, Navarro JM, Pérez-Pérez J, García-Sánchez F, Gómez-Gómez A, Porras I et al., Deficit irrigation and rootstock: their effects on water relations, vegetative development, yield, fruit quality and mineral nutrition of Clemenules mandarin. Tree Physiol 26:1537-1548 (2006).

6 Treeby MT, Henriod RE, Bevington KB, Milne DJ and Storey R, Irrigation management and rootstock effects on navel orange [Citrus sinensis (L.) Osbeck] fruit quality. Agric Water Manag 91:24-32 (2007).

7 Navarro JM, Pérez-Pérez JG, Romero P and Botía P, Analysis of the changes in quality in mandarin fruit, produced by deficit irrigation treatments. Food Chem 119:1591-1596 (2010).

8 Goldhamer DA and Salinas M, Evaluation of regulated deficit irrigation on mature orange trees grown under high evaporative demand. Proc. Int. Soc. Citriculture IX Congr., pp. 227-231 (2000).

9 Velez JE, Intrigliolo DS and Castel JR, Scheduling deficit irrigation of citrus trees with maximum daily trunk shrinkage. Agric WaterManag 90:197-204 (2007).

10 Pérez-Pérez JG, Robles JM and Botía P, Influence of deficit irrigation in phase III of fruit growth on fruit quality in 'Lane late' sweet orange. Agric Water Manag 96:969-974 (2009).

11 Aguado A, Frías J, García-Tejero I, Romero F, Muriel JL and Capote $\mathrm{N}$, Towards the improvement of fruit-quality parameters in citrus under deficit irrigation strategies. ISRN Agron 2012:940896 (2012). DOI: 10.5402/2012/940896.

12 Davies WJ, Wilkinson S and Loveys B, Stomatal control by chemical signalling and the exploitation of this mechanism to increase water use efficiency in agriculture. New Phytol 153:449-460 (2002).

13 Kang S and Zhang J, Controlled alternate partial root-zone irrigation: its physiological consequences and impact on water use efficiency. $J$ Exp Bot 55:2437-2446 (2004).

14 Lo Bianco R and Francaviglia D, Comparative responses of 'Gala' and 'Fuji' apple trees to deficit irrigation: placement versus volume effects. Plant Soil 357:41-58 (2012).

15 Dos Santos TP, Lopes CM, Rodrigues ML, de Souza CR, Maroco JP, Pereira JS et al., Partial rootzone drying: effects on growth and fruit quality of field-grown grapevines (Vitis vinifera). Funct Plant Biol 30:663-671 (2003).

16 Talluto G, Farina V, Volpe G and Lo Bianco R, Effects of partial rootzone drying and rootstock vigour on growth and fruit quality of 'Pink Lady' apple trees in Mediterranean environments. Crop Pasture Sci 59:785-794 (2008).

17 Dry PR and Loveys BR, Factors influencing grapevine vigour and the potential for control with partial rootzone drying. Aust J Grape Wine Res 4:140-148 (1998).

18 Cifre J, Bota J, Escalona JM, Medrano H and Flexas J, Physiological tools for irrigation scheduling in grapevine (Vitis vinifera L.): an open gate to improve water-use efficiency? Agric Ecosyst Environ 106:159-170 (2005).

19 Francaviglia D, Farina V, Avellone G and Lo Bianco R, Fruit yield and quality responses of apple cvars Gala and Fuji to partial rootzone drying under Mediterranean conditions. J Agric Sci 151:556-569 (2013).

20 Morison Jl, Baker NR, Mullineaux PM and Davies WJ, Improving water use in crop production. Philos Trans R Soc B 363:639-658 (2008).

21 Kirda C, Topaloğlu F, Topçu S and Kaman H, Mandarin yield response to partial root drying and conventional deficit irrigation. Turk J Agric For 31:1-10 (2007). 
22 Sampaio AHR, Coelho Filho MA, Coelho EF, Daniel R, Machado VV, Carvalho GC et al., Partial root drying as strategy for water use optimization in a 'Tahiti' lime orchard under the semi-arid of Bahia State. Acta Hort 928:329-336 (2010).

23 Scalbert A and Williamson G, Dietary intake and bioavailability of polyphenols. J Nutr 130:2073-2085 (2000).

24 Giada MD, Food phenolic compounds: main classes, sources and their antioxidant power, in Oxidative Stress and Chronic Degenerative Diseases - a Role for Antioxidants, ed. by Morales-González JA. InTech, Rijeka, pp. 87-112 (2013).

25 Lu Y, Zhang C, Bucheli P and Wei D, Citrus flavonoids in fruit and traditional Chinese medicinal food ingredients in China. Plant Foods Hum Nutr 61:55-63 (2006).

26 Moriguchi T, Kita M, Tomono Y, Endo-Inagaki T and Omura M, Gene expression in flavonoid biosynthesis: correlation with flavonoid accumulation in developing citrus fruit. Physiol Plant 111:66-74 (2001).

27 Nogata Y, Sakamoto K, Shiratsuchi H, Ishii T, Yano M and Ohta $\mathrm{H}$, Flavonoid composition of fruit tissues of citrus species. Biosci Biotechnol Biochem 70:178-192 (2006).

28 Gattuso G, Barreca D, Gargiulli C, Leuzzi U and Caristi C, Flavonoid composition of citrus juices. Molecules 12:1641-1673 (2007).

29 Di Stefano V, Avellone G, Bongiorno D, Cunsolo V, Muccilli V, Sforza $S$ et al., Applications of liquid chromatography-mass spectrometry for food analysis. J Chromatogr A 1259:74-85 (2012).

30 Tripoli E, La Guardia M, Giammanco S, Di Majo D and Giammanco M, Citrus flavonoids: molecular structure, biological activity and nutritional properties: a review. Food Chem 104:466-479 (2007).

31 Rapisarda P, Bianco ML, Pannuzzo P and Timpanaro N, Effect of cold storage on vitamin $C$, phenolics and antioxidant activity of five orange genotypes [Citrus sinensis (L.) Osbeck]. Postharv Biol Technol 49:348-354 (2008).

32 Li S, Wang Z, Ding F, Sun D, Ma Z, Cheng Y et al., Content changes of bitter compounds in 'Guoqing No. 1' Satsuma mandarin (Citrus unshiu Marc.) during fruit development of consecutive 3 seasons. Food Chem 145:963-969 (2014).

33 Lo Bianco R, Responses of apple to partial root-zone drying: a review, in Irrigation Management, Technologies and Environmental Impact, ed. by Ali MH. Nova Science Publishers, New York, NY, pp. 71-86 (2013).

34 Consoli S, Stagno F, Roccuzzo G, Cirelli GL and Intrigliolo F, Sustainable management of limited water resources in a young orange orchard. Agric Water Manag 132:60-68 (2014).

35 González-Altozano P and Castel JR, Regulated deficit irrigation in 'Clementina de Nules' citrus trees. I. Yield and fruit quality effects. $J$ Hort Sci Biotechnol 74:706-713 (1999).

36 Ballester C, Castel J, Intrigliolo DS, Castel JR, Response of Clementina de Nules citrus trees to summer deficit irrigation. Yield components and fruit composition. Agric Water Manag 98:1027-1032 (2011).

37 Huff A, Nutritional control of regreening and degreening in citrus peel segments. Plant Physiol 73:243-249 (1983).

38 Kader AA, Postharvest Technology of Horticultural Crops. UCANR Publications, Richmond, CA, pp. 55-62 (2002).

39 Iglesias DJ, Tadeo FR, Legaz F, Primo-Millo E and Talon M, In vivo sucrose stimulation of colour change in citrus fruit epicarps: interactions between nutritional and hormonal signals. Physiol Plant 112:244-250 (2001).

40 Giuliano G, Bartley GE and Scolnik PA, Regulation of carotenoid biosynthesis during tomato development. Plant Cell 5:379-381 (1993).

41 Tao J, Zhang S, An X and Zhao Z, Effects of light on carotenoid biosynthesis and color formation of citrus fruit peel. Chin J Appl Ecol 14:1833-1836 (2003).

42 Peterson JJ, Dwyer JT, Beecher GR, Bhagwat SA, Gebhardt SE, Haytowitz DB et al., Flavanones in oranges, tangerines (mandarins), tangors, and tangelos: a compilation and review of the data from the analytical literature. J Food Compos Anal 19:66-73 (2006).

43 Magwaza LS, Opara UL, Cronje PJR, Landahl S and Terry LA, Canopy position affects rind biochemical profile of 'Nules Clementine' mandarin fruit during postharvest storage. Postharv Biol Technol 86:300-308 (2013)

44 Shamloo M, Sharifani M, Garmakhany AD and Seifi E, Alternation of flavonoid compounds in Valencia Orange fruit (Citrus sinensis) peel as a function of storage period and edible covers. Minerva Biotecnol 25:191-197 (2013).

45 Tapas AR, Sakarkar DM and Kakde RB, Flavonoids as nutraceuticals: a review. Trop J Pharmaceut Res 7:1089-1099 (2008). 